\title{
United Kingdom 30-day mortality rates after surgery for pediatric central nervous system tumors
}

\author{
Clinical article
}

\author{
Roddy O'Kane, F.R.C.S.(SN), ${ }^{1}$ Ryan Mathew, M.R.C.S., ${ }^{2}$ \\ Tom Kenny, M.F.P.H., M.B.A., M.Sc., ${ }^{3}$ Charles STIller, M.Sc., ${ }^{4}$ \\ and Paul Chumas, F.R.C.S.(SN) ${ }^{2}$
}

${ }^{1}$ Department of Neurosurgery, Royal Hospital for Sick Children, Glasgow, Scotland; ${ }^{2}$ Department of Neurosurgery, General Infirmary at Leeds, Leeds, England; ${ }^{3}$ National Institute for Health Research, Southampton University, Southampton, England; and ${ }^{4}$ Childhood Cancer Research Group, University of Oxford, Oxford, England

\begin{abstract}
Object. In an increasing culture of medical accountability, 30-day operative mortality rates remain one of the most objective measurements reported for the surgical field. The authors report population-based 30-day postoperative mortality rates among children who had undergone CNS tumor surgery in the United Kingdom.

Methods. To determine overall 30-day operative mortality rates, the authors analyzed the National Registry of Childhood Tumors for CNS tumors for the period 2004-2007. The operative mortality rate for each tumor category was derived. In addition, comparison was made with the 30-day operative mortality rates after CNS tumor surgery reported in the contemporary literature. Finally, by use of a funnel plot, institutional performance for 30-day operative mortality was compared for all units across the United Kingdom.

Results. The overall 30-day operative mortality rate for children undergoing CNS tumor surgery in the United Kingdom during the study period was $2.7 \%$. When only malignant CNS tumors were analyzed, the rate increased to $3.5 \%$. One third of the deaths occurred after discharge from the hospital in which the surgery had been performed. The highest 30 -day operative mortality rate (19\%) was for patients with choroid plexus carcinomas. A total of 20 institutions performed CNS tumor surgery during the study period. Rates for all institutions fell within 2 SDs. No trend associating operative mortality rates and institutional volume was found. In comparison, review of the contemporary literature suggests that the postoperative mortality rate should be approximately $1 \%$.

Conclusions. The authors believe this to be the first report of national 30-day surgical mortality rates specifically for children with CNS tumors. The study raises questions about the 30-day mortality rate among children undergoing surgery for CNS tumors. International consensus should be reached on a minimum data set for outcomes and should include 30-day operative mortality rates.
\end{abstract}

(http://thejns.org/doi/abs/10.3171/2013.5.PEDS12514)

KEY WoRdS • 30-day mortality • pediatric • CNS tumor • oncology

$\mathrm{I}$ nternationally, there is a growing culture of medical accountability ${ }^{8,32}$ in which objective evidence of performance is increasing as a requirement. ${ }^{3,15,16}$ The surgical community is expected to have outcome data at the level of both the individual surgeon and the institution. ${ }^{16}$ Surgeons are expected to be aware of the immediate and long-term outcomes of their patients so that new patients can make informed decisions about if and where they wish to receive treatment. ${ }^{28}$

Unfortunately, no single measurement comprehensively measures surgical performance. Various outcome

Abbreviation used in this paper: NRCT = National Registry of Childhood Tumors. measures have been used, ${ }^{29,30}$ many of which are procedure specific. In neurosurgery these include reduced frequency of seizures after epilepsy surgery, ${ }^{42}$ frequency of postoperative CSF shunt infection, ${ }^{2}$ and frequency of transfusion associated with surgery for craniosynostosis. ${ }^{2}$

Understandably, operative mortality rate remains one of the most objective and concrete outcome measurements, and many surgical specialties routinely use the 30-day operative mortality rate. ${ }^{7,9}$ Somewhat surprisingly, this outcome measure has not been widely embraced by the neurosurgical community. In fact, for pediatric CNS

This article contains some figures that are displayed in color online but in black-and-white in the print edition. 


\section{R. O'Kane et al.}

tumor surgery, much of the literature relates to specific tumor types and usually to those from a single institution. ${ }^{1,2,13,22,31,40,44}$ This literature is further confounded by a lack of standardized criteria for reporting postoperative mortality rates, thereby making objective comparison difficult. Furthermore, this literature is probably biased, reporting more favorable outcomes and not truly reflecting real or population-based mortality rates. ${ }^{41,46}$

In the United Kingdom, pediatric neurosurgery is a subspecialty with a comparatively small volume of work; approximately 300-400 new CNS tumors are operated on each year. ${ }^{11}$ We report here a population-based 30 -day postoperative mortality rate in children who underwent CNS tumor surgery in the United Kingdom during the period 2004-2007. To our knowledge, no such national study, looking solely at 30-day mortality rates among children who underwent neurosurgery for CNS tumors, has been reported. We compared these results from the United Kingdom to those reported in the literature.

\section{Methods}

\section{National Registry of Childhood Tumors Data}

The NRCT is a population-based registry of cancer (including nonmalignant CNS neoplasms) for children younger than 15 years of age in England, Wales, Scotland, and Northern Ireland. It is the largest specialized registry of childhood cancers in the world. ${ }^{43}$ Cases are reported from pediatric oncology principal treatment centers and general (all ages) regional and national cancer registries throughout the United Kingdom. Completeness of ascertainment was recently estimated to be at least $99 \%$ for CNS tumors. ${ }^{18}$ The NRCT codes the topography and morphology of all neoplasms according to the International Classification of Diseases for Oncology, third edition. The NRCT receives copies of death certificates for all deaths of children younger than 20 years in Great Britain for whom neoplasm was the underlying cause of death. Children domiciled in Great Britain are registered in the National Health Service Central Registers, which then supply copies of death certificates regardless of cause of death and notifications of emigration resulting in loss to follow-up. Follow-up information for children not registered in the National Health Service Central Registers (including those who reside in Northern Ireland) is obtained from principal treatment centers and cancer registries.

We defined 30-day mortality as any cause of death within 30 days of the histological diagnosis. To determine 30-day postoperative mortality rates for individual tumor categories and for each neurosurgical unit in the United Kingdom, we examined data from the NRCT for the period 2004-2007. Tumors without histological diagnosis were excluded, as were children with optic nerve glioma because most patients with this tumor do not undergo surgery at the time of diagnosis.

We first calculated the national 30-day mortality rate overall, by tumor category (Table 1 ) and by age at diagnosis (categorized as $<2$ years and 2-14 years). We then calculated 2 sets of expected numbers of deaths, accord-
TABLE 1: Thirty-day postoperative mortality rates among children younger than 15 years of age with a CNS tumor, by tumor type, in the United Kingdom, 2004-2007*

\begin{tabular}{lcc}
\hline \multicolumn{1}{c}{ Tumor Type } & $\begin{array}{c}\text { No. of Deaths/ } \\
\text { Total No. of Patients }\end{array}$ & $\begin{array}{c}\text { Mortality } \\
\text { Rate }(\%)\end{array}$ \\
\hline ependymoma & $3 / 110$ & 2.7 \\
choroid plexus papilloma & $0 / 28$ & 0 \\
choroid plexus carcinoma & $3 / 16$ & 18.8 \\
low-grade astrocytoma & $0 / 399$ & 0 \\
high-grade astrocytoma & $9 / 93$ & 9.7 \\
other glioma & $3 / 68$ & 4.4 \\
medulloblastoma & $5 / 212$ & 2.4 \\
other embryonal & $10 / 77$ & 13.0 \\
germ cell & $1 / 59$ & 1.7 \\
pineal parenchymal & $1 / 24$ & 4.2 \\
craniopharyngioma & $0 / 75$ & 0 \\
other & $0 / 119$ & 0 \\
total & $35 / 1280$ & 2.7 \\
\hline
\end{tabular}

* Data source: National Registry of Childhood Tumors. CNS tumor = International Classification for Childhood Cancer (ICCC)-3 III, Xa (in Tables 1 and 2). A CNS tumor is defined as groups IIla-f and Xa in the third edition of the International Classification of Childhood Cancer. ${ }^{39}$

ing to neurosurgical unit. The first result was obtained by summing the number of cases of each tumor category at the unit and multiplying that sum by the national mortality rate for that tumor category over all tumor categories. The second result was obtained by summing the number of cases in each of the age groups $0-1$ and 2-14 years at the unit and multiplying that sum by the national mortality rate for that age group.

Variation in institutional performance for 30-day mortality rate was examined by use of a funnel plot. The $\mathrm{x}$-axis is the expected number of deaths calculated as above. The y-axis is the number of observed deaths expressed as percentage above or below the expected number of deaths. The funnel is created at 2 (alert line) and 3 (alarm line) SDs that adhere to the basic theory of statistical process control. ${ }^{5}$

We also placed each unit into 1 of 4 categories according to the total number of new patients who underwent surgery during the study period; the numbers of patients in each category were roughly equal. This categorization enabled us to look for any trend associated with operative volume and 30-day mortality rate.

\section{Literature Search}

In May 2011, to examine contemporary institutional series relating to perioperative deaths associated with CNS tumors, we performed an initial literature search in the National Library of Medicine database (PubMed) for the period 1995-2011. We updated this search periodically. Under MeSH and key words, we searched for the following terms: brain neoplasms, neurosurgery, neurosurgical procedures, mortality, post operative complications, and outcome assessment (healthcare). We confined 


\section{Thirty-day mortality rates after surgery for CNS tumors}

our search to 0-18 years and humans. The abstracts were reviewed, relevant articles were retrieved, and references from the relevant articles were examined to identify any additional publications.

\section{Results \\ National Registry of Childhood Tumors Data}

From 2004 through 2007, a total of 1280 patients younger than 15 years of age had undergone surgery for a newly diagnosed CNS tumor. Table 1 shows the distribution of patients by tumor type and 30-day mortality rates. Among the tumor types, astrocytoma accounted for about $33 \%$, medulloblastoma for just over $15 \%$, and ependymoma for just under $10 \%$.

Within 30 days of surgery, 35 children (2.7\%) died. The 30-day mortality rate among children with malignant CNS tumors was $3.5 \%$. Of the 35 deaths, 24 (69\%) occurred in the hospital where the surgery was performed, $2(6 \%)$ in a different hospital, $6(17 \%)$ in a hospice, and 3 (9\%) at home.

The highest 30-day postoperative mortality rate, $19 \%$, was for children with choroid plexus carcinoma. The 30-day mortality rate for children with embryonal tumors other than medulloblastoma (principally primitive neuroectodermal tumor and atypical teratoid rhabdoid tumor) was $13 \%$; for children with high-grade astrocytomas, the rate was almost $10 \%$. Rates for children with tumors in the remaining categories were below 5\%. These categories include the 3 more common CNS tumors of children: low-grade glioma (no deaths), medulloblastoma $(2.4 \%)$, and ependymoma (2.7\%). No deaths occurred within 30 days after surgery among children with craniopharyngioma or choroid plexus papilloma (including atypical choroid plexus papilloma). The 30-day mortality rate was higher for children younger than 2 years of age $(13 / 184,7.1 \%)$ than for those $2-14$ years of age $(22 / 1096$, $2.0 \%$ ) (chi-square $[1 \mathrm{df}]=13.3, \mathrm{p}<0.001)$.

\section{Institutional Performance}

From 2004 through 2007 in the United Kingdom, surgery for CNS tumors in children was performed at 20 institutions. Funnel plots illustrate the institutional performance in relation to 30 -day mortality rates, adjusting for tumor type (Fig. 1) and age at diagnosis (Fig. 2). In both analyses, 30-day postoperative mortality rates fell within the control limits of 2 SDs for all units. In terms of institutional volume of surgeries, no association was found between volume and 30-day mortality rates (Table 2).

\section{Literature Search}

Relevant articles from the literature are shown in Table 3 . The contemporary literature reports postoperative mortality rates after surgery of brain tumors in children to be about $1 \% .^{2,13,22,33}$

\section{Discussion}

There is a paucity of information in the literature about deaths after pediatric CNS tumor surgery. The mortality rate information that is available relates to either single institutions and/or in-house mortality. The singleinstitution studies probably represent best practice, and the in-house studies do not allow for direct comparison because the only criterion for recording the death is that it occurred during the same admission as the surgery. The only population-based study that we found is from Norway, and it included adults and children. Although that study does not give a breakdown by tumor types for the deaths among children, it does record the overall 30-day mortality rate for children younger than 16 years as $1.4 \%$ (10 of 731 patients) for the period 1990-2008. ${ }^{35}$ Our study found 30-day mortality rates in the United Kingdom to be nearly twice that in Norway $(2.7 \%$ for CNS tumors and $3.5 \%$ for malignant CNS tumors).

The reason for the relatively high 30-day mortality rate in the United Kingdom is unclear and might reflect a statistical anomaly because only a small number of deaths occur within 30 days of surgery. If this difference in mortality rates is real, then other potential factors need to be explored. Such factors might include delayed presentation (that is, more children presenting in extremis) in the United Kingdom. The median interval between symptom onset and diagnosis in the United Kingdom is reported to be 3.3 months, ${ }^{45}$ which is longer than the interval reported from other countries such as Germany (24 days) ${ }^{26}$ and Switzerland (60 days). ${ }^{12}$ Other potential explanations for the difference in rates might include patient selection, surgical management (including pediatric training and experience of the surgical team), perioperative care, and thresholds for withdrawing treatment.

\section{Literature Review}

The most recent publication from the Toronto group ${ }^{13}$ prospectively examined complications, including deaths after all neurosurgical procedures, at their institution. They reported no deaths after 190 brain tumor procedures over a 2-year period (2005-2007). The Amsterdam group $^{22}$ retrospectively reported a mortality (defined as death within 30 days of procedure) rate of $0.8 \%$ for 121 patients undergoing brain tumor surgery over a period of 7.5 years (1999-2007). The Pittsburgh group ${ }^{2}$ retrospectively reported an operative mortality (defined as death within 30 days of procedure) rate of $1(1 \%)$ in 100 patients consecutively undergoing craniotomy for tumor.

Smith et al. ${ }^{33}$ reported on a population registry from the Nationwide Inpatient Sample hospital discharge database that covers approximately $20 \%$ of all inpatient admissions for nonfederal hospitals in the United States. They identified all patients 18 years of age or younger who were admitted for craniotomy for brain neoplasms. Mortality was defined as an in-hospital death. For the final period in this study, 1997-2000, the reported mortality rate was $1.2 \%$. The in-hospital mortality rate was also noted to be higher for the lowest volume hospitals (1-4 cases/year) than for the highest volume hospitals $(\geq 21$ cases/year), $2.3 \%$ versus $1.4 \%$, respectively. The relationship between in-house mortality rates and 30-day mortality rates has been studied, and the correlation is moderately good $(\kappa>0.40)$ although the correlation varies, depending on the condition studied. ${ }^{7}$ It should be noted that for most of the studies mentioned above, the upper age 
R. O’Kane et al.

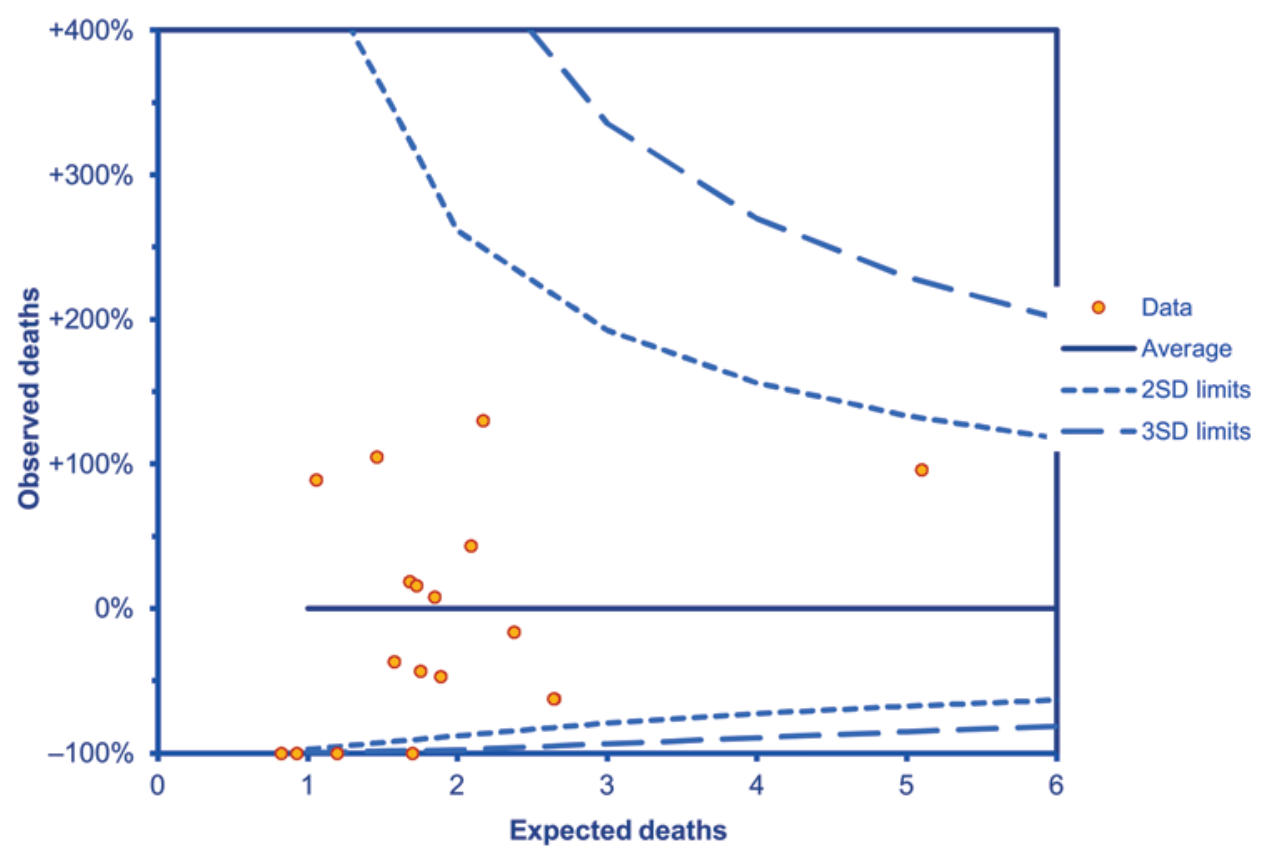

FIG. 1. Funnel plot of 30-day mortality rate, by institution, adjusting for tumor type, based on data from NRCT.

limit was higher than the 15 th birthday, so the mean age of patients in the study would be higher than that in our study, and the 30-day mortality rate would be expected to be correspondingly lower.

Although more studies of early postoperative mortality rates have been conducted among adults than among children, these studies are largely from US administrative data sets and report in-house mortality rates, often for a specific tumor type. Barker et al. ${ }^{4}$ showed a decrease in in-house mortality rates, from $4.8 \%$ to $1.8 \%$, after supratentorial primary brain tumor surgery over the period 1980-2000. They also found that large-volume units had lower mortal- ity rates and after-discharge disposition than low-volume units. In fact, the mortality rate after craniotomy in units with 5 or fewer admissions per year was $4.5 \%$; and in units with more than 42 admissions per year, the rate was $1.5 \%$. In Norway, the national data set also showed that the 30day mortality rates decreased over time for adult patients to the current rate of $2.2 \%$. These authors also found that 30 -day mortality rates were higher for older patients $(>70$ years of age) and those with a poor prognosis.

\section{Tumor Categories}

The relative frequencies of tumor types found in this

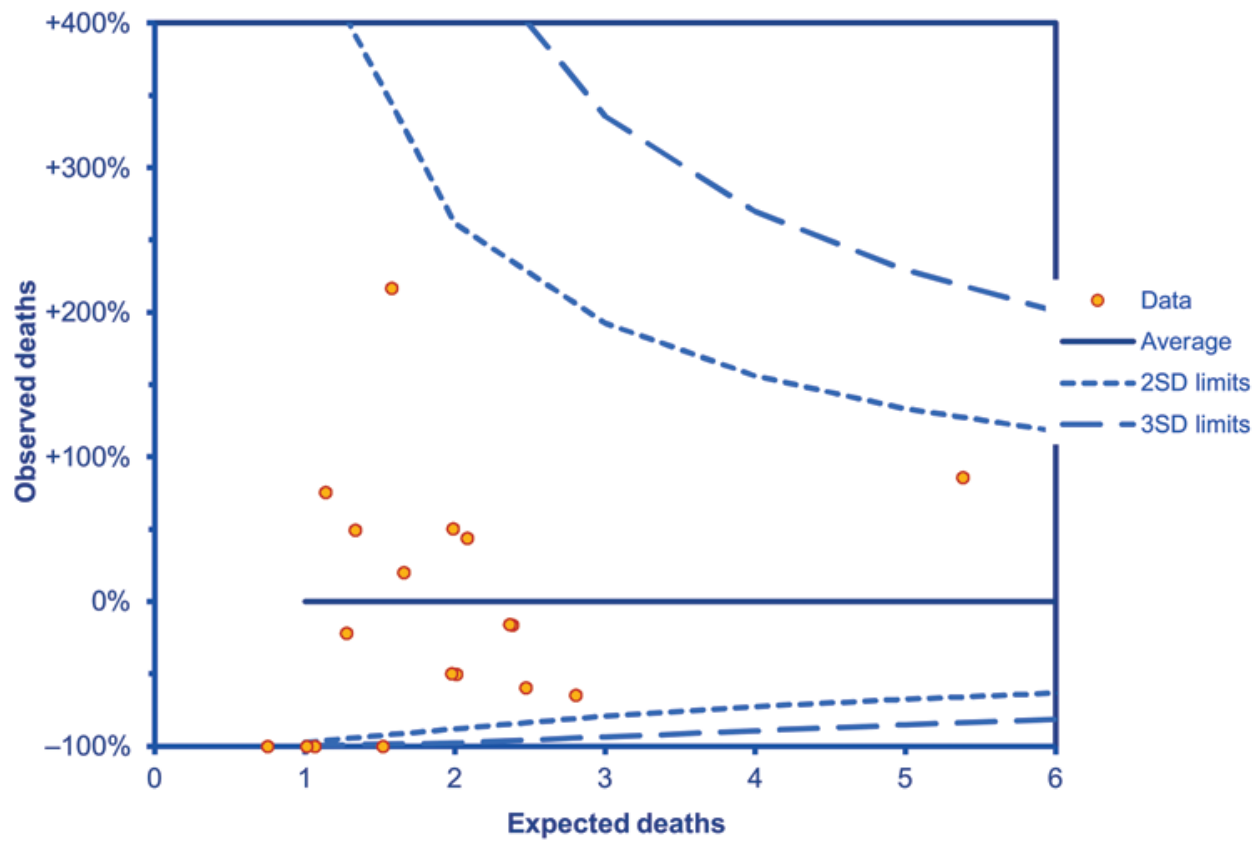

Fig. 2. Funnel plot of 30-day mortality rate, by institution, adjusting for age at diagnosis, based on data from NRCT. 


\section{Thirty-day mortality rates after surgery for CNS tumors}

TABLE 2: Thirty-day mortality rates among children younger than 15 years of age with a CNS tumor, after grouping of institutions by number of procedures performed over the study period, in the United Kingdom, 2004-2007*

\begin{tabular}{lcccccc}
\hline $\begin{array}{c}\text { No. of Patients Undergoing } \\
\text { Surgery at a Unit }\end{array}$ & $\begin{array}{c}\text { No. of } \\
\text { Units }\end{array}$ & $\begin{array}{c}\text { Total No. of } \\
\text { Patients }\end{array}$ & $\begin{array}{c}\text { 30-Day Mortality } \\
\text { Rate (\%) }\end{array}$ & $\begin{array}{c}\text { No. of Observed } \\
\text { Deaths }\end{array}$ & $\begin{array}{c}\text { Expected No. } \\
\text { of Deaths } \dagger\end{array}$ & $\begin{array}{c}\text { Expected No. } \\
\text { of Deaths }\end{array}$ \\
\hline$>100$ & 2 & 297 & 3.7 & 11 & 7.75 & 8.19 \\
$79-86$ & 4 & 328 & 2.1 & 7 & 8.80 & 9.21 \\
$60-76$ & 5 & 354 & 3.4 & 12 & 8.95 & 9.31 \\
$3-53$ & 9 & 302 & 1.7 & 5 & 9.50 & 8.29 \\
\hline * Data source: National Registry of Childhood Tumors. & & & & & \\
† Adjusted for tumor type. & & & & & &
\end{tabular}

study were similar to those reported from the NRCT for the time period $1991-2000^{38}$ and to those quoted in pediatric neurosurgery textbooks. ${ }^{27}$

For choroid plexus carcinomas, the postoperative mortality rate was particularly high, $19 \%$. Choroid plexus tumors occur at a higher incidence in the first few years of life, ${ }^{27}$ and blood loss represents a significant surgical risk for these young patients. ${ }^{24}$ Total surgical excision is the most effective treatment for choroid plexus carcinomas. ${ }^{6,23}$ Preoperative intravascular embolization should be considered and has been shown to help with the surgical management of these lesions. ${ }^{23}$ Neoadjuvant chemotherapy can also help decrease tumor size and vascularity. ${ }^{36}$ Second-look surgery should also be considered if initial surgery fails to achieve a gross-total resection. ${ }^{6}$ The high 30 -day mortality rate found in this study raises the question of whether the care of patients with these rare tumors should be concentrated in a limited number of institutions to increase the experience in managing them.

For medulloblastomas, the 30-day operative mortality rate was $2.4 \%$. We were unable to find any series reporting in-house or 30-day mortality rates for this tumor type, although no "surgical mortality" has been reported, even for patients who had brainstem invasion. ${ }^{14}$ Likewise, we could find little data relating to perioperative mortality rates for ependymomas..$^{25,44}$ The St. Jude team, even with their aggressive surgical approach to posterior fossa ependymomas, has not had a death within 30 days since the mid-1980s; their case series is now more than 200 ependymomas (F. Boop, personal communication, 2011). The rate for ependymoma/subependymoma in the Norway registry combined series of adult and pediatric cases is $0.7 \% .35$ The 30 -day mortality rate of $2.7 \%$ for ependymoma in the United Kingdom is therefore higher than expected.

Our study has also shown particularly high 30-day mortality rates for patients with high-grade gliomas $(9.7 \%)$ and other embryonal tumors (13\%). This finding is in accord with the finding from the Norway series that patients with tumors with a poor prognosis are at increased risk for perioperative death. That said, the 30-day mortality rate for high-grade gliomas in adults and children was $3.9 \%$ in the Norway study. ${ }^{35}$ Comparison of the findings for the other embryonal tumors was not possible because the Norway registry has combined medulloblastoma with primitive neuroectodermal tumors $(4.1 \%) .{ }^{35}$

\section{Institutional Comparisons of UK Data}

When the number of patients is sufficiently large, comparison of population-based (registry) data should allow for national and international comparisons with limited stratification. However, when comparing institutions, stratification is necessary. As described earlier, we were able to stratify by tumor histological subtype and by patient age (age is established as an independent risk factor for many types of CNS tumor in children). Although the NRCT is evolving to allow data collection on tumor staging and tumor subtype/biology, the fundamental problem with stratification of this sort is that for many tumor types, the numbers will become too small for statistical interpretation.

To explore potential differences in 30-day mortality rates between institutions, we used funnel plots because they are relatively simple to construct, are easy to interpret, and overcome the limitations of ranking. ${ }^{17,19-21,37}$ This method is also used by the Society for Cardiothoracic Surgery in the United Kingdom. ${ }^{8,9}$ Figures 1 and 2 show that all institutions that performed pediatric CNS tumor surgery in the United Kingdom fell within the set binomial control limits when the data were stratified by tumor type and age at diagnosis, respectively. The small number of operations being performed by some units in the United Kingdom means that it is virtually impossible for them to be outliers, resulting in a very wide mouth to the funnel. However, we also found no evidence of an association between annual number of patients at a center and 30-day mortality rate. In contrast, Smith et al. ${ }^{33}$ and Barker et al. ${ }^{4}$ did note an association between center volume and mortality rates for children and adults, respectively. Despite the fact that proportionally more of the units in the United Kingdom would have been defined as large, according to the criteria used by Smith et al., the overall mortality rate would again appear to be higher in the United Kingdom (approximately twice the rate in the United States). Although the study by Smith et al. is not population based, it was based on a $20 \%$ sample of admissions to nonfederal hospitals, making it less likely that the UK data can be explained by recruitment bias alone (although the US data are not directly comparable because they limited mortality to "in hospital"). Smith et al. found that approximately one third of the 30-day deaths occurred after discharge from the hospital in which the surgery was performed. 


\section{R. O'Kane et al.}

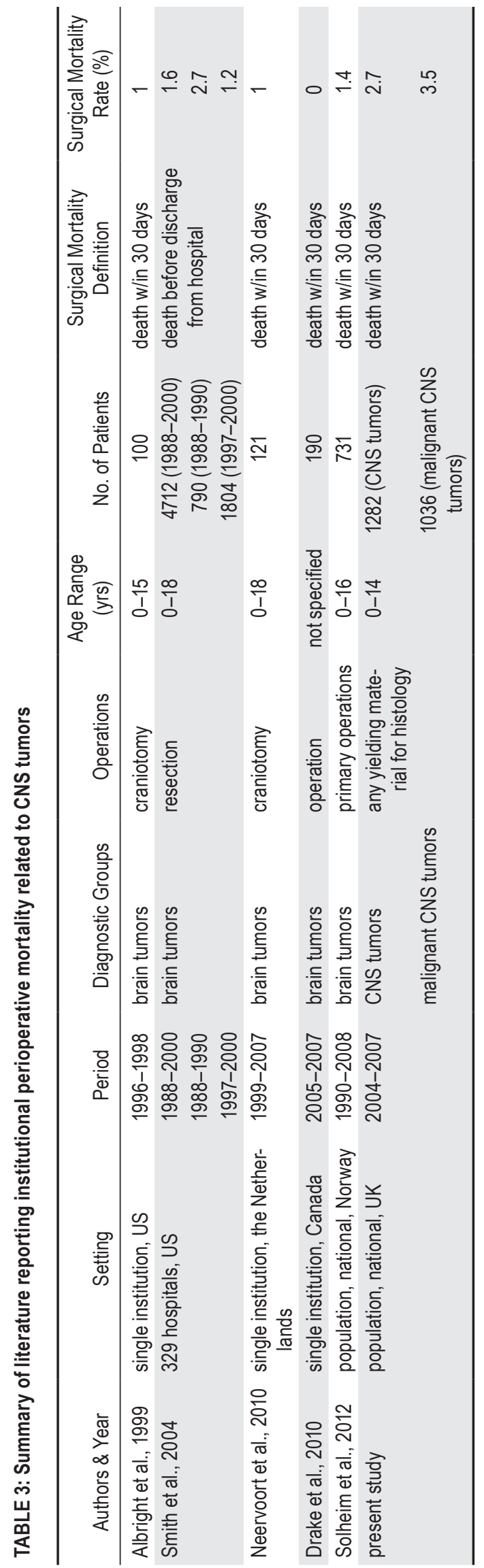

The US Agency for Healthcare Research and Quality has endorsed surgical mortality rate after craniotomies as an Inpatient Quality Indicator. However, as pointed out by Solheim et al., ${ }^{35}$ the low rate of deaths soon after surgery for CNS tumors makes it unlikely that this measure will be sufficiently sensitive. Certainly, even with the higher mortality rate seen in the United Kingdom, no difference could be shown between surgical units because of the small number of cases being performed in each unit. Furthermore, the smaller the number of cases being analyzed, the greater the need to stratify by risk factor; for registry data, it is usually only possible to stratify by age and by diagnosis.

Many publications have tried to examine whether individual surgeon volume (experience) is more important than center volume with regard to outcome..$^{10,34}$ Because the NRCT does not collect data on the individual surgeon performing the procedure, we therefore cannot comment on the association. Regardless, the small number of tumor operations being performed by each surgeon would preclude using 30-day mortality rate as a possible differentiator.

\section{Limitations of This Study}

As has been established by historical convention, we selected the 30-day postoperative mortality rate. We defined 30-day operative mortality as any death, regardless of cause, within 30 days of the surgical operation that established the diagnosis. In the literature, there is variation in what is included in perioperative mortality rates; some authors include deaths occurring after 30 days but during the same admission or exclude deaths occurring within 30 days but occurring outside the hospital of surgery.

The main study limitation is the inability to reliably compare the United Kingdom results with other national data sets, other than the overall mortality rate for children reported for the Norway population. This lack of data for 30-day mortality is not restricted to pediatric neurosurgery but to all aspects of neurosurgery in general. If we are unable to record this simple outcome measure, it is not surprising that there is so little in the literature regarding morbidity. It is therefore imperative that a minimum data set for mortality and morbidity be agreed on internationally and that health care purchasers fund such data collection.

\section{Conclusions}

We believe this article to be the first to report national 30-day surgical mortality rates specifically for children with CNS tumors. Although these data have been collected for many years in the United Kingdom, they have been underused by clinicians to inform and aid in the management of patients with CNS tumors. We would argue that the neurosurgical community needs to agree on a minimum data set to enable national and international comparison and that this data set should include 30-day operative mortality rates. However, to facilitate accurate data collection, resources from those who commission the surgery would be required. The study reported here raises questions over the 30-day mortality rate 


\section{Thirty-day mortality rates after surgery for CNS tumors}

for children undergoing surgery for CNS tumors in the United Kingdom. This rate appears to be approximately 2 times that reported in other registries and approximately 3 times that reported in contemporary institutional series. Unless a reasonable explanation becomes apparent, and despite the fact that no association between volume and outcome was found in this study, we suggest that all children at high risk undergo this surgery in a limited number of institutions to allow surgical experience to develop and allow a more robust audit.

\section{Disclosure}

The Childhood Cancer Research Group receives funding from the Department of Health, the National Cancer Intelligence Network, the Scottish Government, and CHILDREN with CANCER UK. The views expressed here are those of the authors and not necessarily of any of these funding bodies.

Author contributions to the study and manuscript preparation include the following. Conception and design: Chumas. Acquisition of data: Mathew, Stiller. Analysis and interpretation of data: Chumas, O'Kane, Stiller. Drafting the article: all authors. Critically revising the article: all authors. Reviewed submitted version of manuscript: all authors. Approved the final version of the manuscript on behalf of all authors: Chumas. Statistical analysis: Stiller. Study supervision: Chumas. Literature search: Mathew.

\section{References}

1. Akay KM, Izci Y, Baysefer A, Atabey C, Kismet E, Timurkaynak E: Surgical outcomes of cerebellar tumors in children. Pediatr Neurosurg 40:220-225, 2004

2. Albright AL, Pollack IF, Adelson PD, Solot JJ: Outcome data and analysis in pediatric neurosurgery. Neurosurgery 45:101-106, 1999

3. American Board of Medical Specialties: Maintenance of Certification: Competencies and Criteria. (http://www.abms. org/Maintenance_of_Certification/MOC_competencies. aspx) [Accessed May 14, 2013]

4. Barker FG II, Curry WT Jr, Carter BS: Surgery for primary supratentorial brain tumors in the United States, 1988 to 2000: the effect of provider caseload and centralization of care. Neuro Oncol 7:49-63, 2005

5. Benneyan JC, Lloyd RC, Plsek PE: Statistical process control as a tool for research and healthcare improvement. Qual Saf Health Care 12:458-464, 2003

6. Berger C, Thiesse P, Lellouch-Tubiana A, Kalifa C, PierreKahn A, Bouffet E: Choroid plexus carcinomas in childhood: clinical features and prognostic factors. Neurosurgery 42:470-475, 1998

7. Borzecki AM, Christiansen CL, Chew P, Loveland S, Rosen AK: Comparison of in-hospital versus 30-day mortality assessments for selected medical conditions. Med Care 48:11171121,2010

8. Bridgewater B, Cooper G, Livesey S, Kinsman R: Maintaining Patients' Trust: Modern Medical Professionalism 2011. (http://www.scts.org/_userfiles/resources/634420268996 790965_SCTS_Professionalism_FINAL.pdf) [Accessed May $14,2013]$

9. Bridgewater B, Keogh B, Kinsman R, Walton P: Sixth National Adult Cardiac Surgical Database Report 2008. (http://www.e-dendrite.com/files/13/file/Pages $\% 20$ from $\% 20$ NACSD\%202008.pdf) [Accessed May 14, 2013]

10. Chumas P, Kenny T, Stiller C: Subspecialisation in neurosurgery-does size matter? Acta Neurochir (Wien) 153:12311236,2011

11. Chumas P, Pople I, Mallucci C, Steers J, Crimmins D: British paediatric neurosurgery-a time for change? Br J Neurosurg 22:719-728, 2008
12. Dobrovoljac M, Hengartner H, Boltshauser E, Grotzer MA: Delay in the diagnosis of paediatric brain tumours. Eur J Pediatr 161:663-667, 2002

13. Drake JM, Riva-Cambrin J, Jea A, Auguste K, Tamber M, Lamberti-Pasculli M: Prospective surveillance of complications in a pediatric neurosurgery unit. Clinical article. J Neurosurg Pediatr 5:544-548, 2010

14. Gajjar A, Sanford RA, Bhargava R, Heideman R, Walter A, Li $\mathrm{Y}$, et al: Medulloblastoma with brain stem involvement: the impact of gross total resection on outcome. Pediatr Neurosurg 25:182-187, 1996

15. General Medical Council: Good Medical Practice. (http:// www.gmc-uk.org/static/documents/content/GMP_2013. pdf_51447599.pdf) [Accessed May 17, 2013]

16. Hammers R, Anzalone S, Sinacore J, Origitano TC: Neurosurgical mortality rates: what variables affect mortality within a single institution and within a national database? Clinical article. J Neurosurg 112:257-264, 2010

17. Kirkham JJ, Bouamra O: The use of statistical process control for monitoring institutional performance in trauma care. J Trauma 65:1494-1501, 2008

18. Kroll ME, Murphy MF, Carpenter LM, Stiller CA: Childhood cancer registration in Britain: capture-recapture estimates of completeness of ascertainment. Br J Cancer 104:1227-1233, 2011

19. Marshall T, Mohammed MA, Rouse A: A randomized controlled trial of league tables and control charts as aids to health service decision-making. Int J Qual Health Care 16: 309-315, 2004

20. Mayer EK, Bottle AP, Rao CB, Darzi AW, Athanasiou T: Funnel plots and their emerging application in surgery. Ann Surg 249:376-383, 2009

21. Mohammed MA, Deeks JJ: In the context of performance monitoring, the caterpillar plot should be mothballed in favor of the funnel plot. Ann Thorac Surg 86:348-349, 2008 (Letter)

22. Neervoort FW, Van Ouwerkerk WJ, Folkersma H, Kaspers GJ, Vandertop WP: Surgical morbidity and mortality of pediatric brain tumors: a single center audit. Childs Nerv Syst 26:1583-1592, 2010

23. Pencalet P, Sainte-Rose C, Lellouch-Tubiana A, Kalifa C, Brunelle F, Sgouros S, et al: Papillomas and carcinomas of the choroid plexus in children. J Neurosurg 88:521-528, 1998

24. Piastra M, Di Rocco C, Tempera A, Caresta E, Zorzi G, Tosi F, et al: Massive blood transfusion in choroid plexus tumor surgery: 10-years' experience. J Clin Anesth 19:192-197, 2007

25. Pierre-Kahn A, Hirsch JF, Roux FX, Renier D, Sainte-Rose C: Intracranial ependymomas in childhood. Survival and functional results of 47 cases. Childs Brain 10:145-156, 1983

26. Reulecke BC, Erker CG, Fiedler BJ, Niederstadt TU, Kurlemann G: Brain tumors in children: initial symptoms and their influence on the time span between symptom onset and diagnosis. J Child Neurol 23:178-183, 2008

27. Rorke LB: Pathology of brain and spinal cord tumours, in Choux M, Di Rocco C, Hockley A, et al (eds): Pediatric Neurosurgery. Churchill Livingstone, 1999, pp 395-426

28. Royal College of Surgeons of England: Good Surgical Practice. London: Royal College of Surgeons of England, 2008

29. Royal College of Surgeons of England: Measuring and Using Outcomes from Surgery. London: Royal College of Surgeons of England, 2008

30. Royal College of Surgeons of England: Measuring Surgical Outcomes. (http://www.rcseng.ac.uk/media/media-back ground-briefings-and-statistics/measuring-surgical-outcomes) [Accessed May 14, 2013]

31. Sandri A, Sardi N, Genitori L, Giordano F, Peretta P, Basso ME, et al: Diffuse and focal brain stem tumors in childhood: prognostic factors and surgical outcome. Experience in a single institution. Childs Nerv Syst 22:1127-1135, 2006

32. Shaw K, Cassel CK, Black C, Levinson W: Shared medical 
regulation in a time of increasing calls for accountability and transparency: comparison of recertification in the United States, Canada, and the United Kingdom. JAMA 302:20082014, 2009

33. Smith ER, Butler WE, Barker FG II: Craniotomy for resection of pediatric brain tumors in the United States, 1988 to 2000: effects of provider caseloads and progressive centralization and specialization of care. Neurosurgery 54:553-565, 2004

34. Solheim O, Cappelen J: Bigger is bigger. Better is better. Acta Neurochir (Wien) 153:1237-1245, 2011 (Letter)

35. Solheim O, Jakola AS, Gulati S, Johannesen TB: Incidence and causes of perioperative mortality after primary surgery for intracranial tumors: a national, population-based study. Clinical article. J Neurosurg 116:825-834, 2012

36. Souweidane MM, Johnson JH Jr, Lis E: Volumetric reduction of a choroid plexus carcinoma using preoperative chemotherapy. J Neurooncol 43:167-171, 1999

37. Spiegelhalter DJ: Funnel plots for comparing institutional performance. Stat Med 24:1185-1202, 2005

38. Steliarova-Foucher E, Stiller C, Lacour B, Kaatsch P: International classification of childhood cancer, third edition. Cancer 103:1457-1467, 2005

39. Stiller C: Childhood Cancer in Britain: Incidence, Survival, Mortality. Oxford: Oxford University Press, 2007

40. Sutton LN, Goldwein J, Perilongo G, Lang B, Schut L, Rorke L, et al: Prognostic factors in childhood ependymomas. Pediatr Neurosurg 16:57-65, 1990

41. Syin D, Woreta T, Chang DC, Cameron JL, Pronovost PJ, Makary MA: Publication bias in surgery: implications for informed consent. J Surg Res 143:88-93, 2007
42. Vickrey BG, Hays RD, Engel J Jr, Spritzer K, Rogers WH, Rausch R, et al: Outcome assessment for epilepsy surgery: the impact of measuring health-related quality of life. Ann Neurol 37:158-166, 1995

43. Vincent TJ, Bayne AM, Brownbill PA, Stiller CA: Methods, in Stiller CA (ed): Childhood Cancer in Britain: Incidence, Survival, Mortality. Oxford: Oxford University Press, 2007, pp 7-21

44. Vinchon M, Soto-Ares G, Riffaud L, Ruchoux MM, Dhellemmes P: Supratentorial ependymoma in children. Pediatr Neurosurg 34:77-87, 2001

45. Wilne S, Collier J, Kennedy C, Jenkins A, Grout J, Mackie S, et al: Progression from first symptom to diagnosis in childhood brain tumours. Eur J Pediatr 171:87-93, 2012

46. Yoshimoto Y: Publication bias in neurosurgery: lessons from series of unruptured aneurysms. Acta Neurochir (Wien) 145: 45-48, 2003

Manuscript submitted October 18, 2012.

Accepted May 9, 2013.

Parts of this study were presented at the European Society of Pediatric Neurosurgery, Antalya, Turkey, April 2010, and the Society of British Neurological Surgeons, Leeds, UK, September 2012.

Please include this information when citing this paper: published online June 28, 2013; DOI: 10.3171/2013.5.PEDS12514. Address correspondence to: Paul Chumas, M.D., F.R.C.S.(SN), Department of Neurosurgery, General Infirmary at Leeds, Leeds LS1 3EX, United Kingdom. email: p.chumas@leeds.ac.uk. 